\title{
Marked Retroperitoneal Lymphadenopathy in Hairy Cell Leukemia: A Case Report
}

\author{
R.E. Shackelford M. Heldmann F. Eskandari N. Joshi J. Browning \\ N. Maxwell J. Coteligam \\ Department of Pathology, LSU Health Shreveport, Shreveport, La., USA
}

\section{Key Words}

Hairy cell leukemia $\cdot$ Retroperitoneal lymphadenopathy

\begin{abstract}
Hairy cell leukemia $(\mathrm{HCL})$ is uncommonly associated with lymphadenopathy, while retroperitoneal lymphadenopathy is extremely uncommon. We report on a patient with a 12-year history of $\mathrm{HCL}$ who developed painless jaundice and ascites, accompanied by positional discomfort with persistent nausea. Computed tomography examination revealed 2 large retroperitoneal masses, which at autopsy consisted of $\mathrm{HCL}$ with focally intermixed pancreatic and peripancreatic tissue. Lymphadenopathy was not identified above the diaphragm or below the aortic bifurcation. No vasculitis or an unusual $\mathrm{HCL}$ histology was identified. As previous reports, our findings suggest that $\mathrm{HCL}$ with massive lymphadenopathy has a specific site predilection, but it is not necessarily accompanied by vasculitis or an unusual histology.
\end{abstract}

(c) 2013 S. Karger AG, Basel

\section{Introduction}

Hairy cell leukemia (HCL) is an uncommon, indolent, B-cell leukemia that usually presents with chronic fatigue, right upper quadrant pain, splenomegaly, bleeding, and infections secondary to cytopenias. Malignant cells with cytoplasmic projections are seen in the bone marrow, spleen, and at low levels in circulation [1-3]. There are approximately 1,000 and 1,600 new cases of HCL per year in the US and Europe, respectively. The prevalence of the disease is unknown, although it likely exceeds the yearly HCL incidence [4]. HCL is diagnosed based on blood counts including thrombocytopenia, anemia, leukopenia, neutropenia, 
monocytopenia, and characteristic immunohistologic (IHC) and cell-morphologic studies showing cells with cytoplasmic projections, oval or indented nuclei ('bean-shaped'), and a 'fried egg' appearance on bone marrow biopsy due to abundant pale blue cytoplasm [5-7].

\section{Case Report}

A 73-year-old male presented with a diagnosis of acute respiratory and renal failure, a large abdominal mass, ascites, a white blood cell count of $8.09 \times 10^{3} / \mu \mathrm{l}$, a hemoglobin value of $12.5 \mathrm{~g} / \mathrm{dl}$, and a hematocrit value of $36.1 \%$. His past medical history included splenectomy, hypertension, and a diagnosis of HCL from 12 years earlier. Prior to admission the patient had a 1-month history of positional discomfort, with occasional nausea and vomiting, and a 1-week history of painless jaundice. Abdominal axial computed tomography (CT) with intravenous and gastrointestinal contrast revealed a large retroperitoneal mass encasing the superior mesenteric artery, displacing the stomach and infiltrating into the liver (fig. 1). The patient was transferred to the medical Intensive Care Unit for further management and placed on a ventilator. After discussion with the attending physician, the family requested the patient be extubated and pronounced 'do not resuscitate'. The patient died the following day.

Autopsy revealed moderate ascites consisting of serosanguineous fluid (550 $\mathrm{ml})$ and 2 retroperitoneal masses. The first mass was $3.5 \mathrm{~cm}$ below the xyphoid process and measured $7.7 \times 5.0 \times 3.5 \mathrm{~cm}$. The second mass was immediately below the first and measured $16.0 \times$ $10.0 \times 9.5 \mathrm{~cm}$. Approximately $80 \%$ of the larger mass was removed and weighed $825 \mathrm{~g}$. No nodal enlargement was found below the aortic bifurcation. Histologic examination of the mass by standard hematoxylin and eosin (HE) staining revealed extensive HCL cells (fig. 2a). Additionally, IHC analysis revealed that the tumor cells were CD20 and tartrate-resistant acid phosphatase (TRAP) positive (fig. $2 \mathrm{~b}$ ). The IHC analysis was performed in the LSU Health Shreveport Pathology Histology Immunohistochemistry Procedures Pathology Services using antibodies from Cell Marque (Rocklin, Calif., USA) following the manufacturer's recommended protocols.

\section{Discussion}

HCL accounts for $2 \%$ of all leukemias [1]. It was first recognized in 1923 by Ewald who described it as 'leukämische Reticuloendotheliose' [2]. Later Bouroncle et al. [3] described it as a distinct clinicopathologic entity, and in 1966 Schrek and Donnelly gave it its present name [6]. HCL is an indolent, chronic, B-cell, lymphoproliferative disorder involving the bone marrow and spleen, often accompanied by reactive marrow fibrosis and peripheral blood cytopenias, especially monocytopenia [2, 5-7]. HCL is an expansion of phenotypically activated mature B cells, expressing CD19, CD20, CD22, CD25, DBA.44, annexin A1, CD11c, and $\mathrm{CD} 103$, with clonal immunoglobulin gene rearrangements and monoclonal surface immunoglobulins. The cells are also TRAP positive, although this test is now less often performed [5-7]. Although generally considered CD10 and CD5 negative, weak CD10 and CD5 expression is seen in approximately 26 and $5 \%$ of HCL, respectively. The median age at presentation is 52 years with a 4:1 male predominance. Chromosomal abnormalities have been documented in HCL; however, none are recognized as specific to HCL, although the disease does show the BRAF-V600E-activating mutation in the majority of cases [1,5-9]. 
While lymphadenopathy occurs in approximately $20 \%$ of all individuals with HCL, it is not usually considered clinically significant $[1,5-7]$. Massive retroperitoneal lymphadenopathy in HCL is extremely uncommon, with most examples limited to case reports [10-12]. The largest study, based on 12 cases, found massive retroperitoneal lymphadenopathy typically followed long-standing disease, with an average appearance 9 years after HCL diagnosis (range 3-25 years, 8/12 cases), extensive bone marrow involvement (12/12 cases), with retroperitoneal lymphadenopathy measuring $4-20 \mathrm{~cm}$, with bulkier disease more likely to involve the hepatic porta, gastric outlet, and pancreas, and little or no nodal enlargement below the aortic bifurcation (12/12 cases, $10-12)$. 11/12 patients received chemotherapy prior to retroperitoneal lymphadenopathy development and only 1 patient initially presented with massive retroperitoneal lymphadenopathy [10].

Other case reports describe similar findings, one with massive retroperitoneal lymphadenopathy being a terminal event after a long disease course, as in our case [10-13]. Two of these studies suggested that vasculitis accompanies HCL retroperitoneal lymphadenopathy $[11,13]$, while the larger study by Mercieca et al. [10] suggested that in some of these patients lymphadenopathy follows a change in the disease as reflected by the resistance to chemotherapy and histologically by the appearance of larger, more primitive cells. We identified no vasculitis or HCL cells with an unusual histology for this disease. The location of the lymphadenopathy, however, is very similar to that given in previous reports [10-13]. Our findings suggest that HCL with massive lymphadenopathy appears after an unusually long disease course and has a predilection for the retroperitoneum above the aortic bifurcation and below the diaphragm, but it is not necessarily accompanied by vasculitis or a change away from the typical HCL histology.

\section{Acknowledgement}

We would like to thank Lisa LaChance for proofreading the manuscript.

\section{References}

$\checkmark 1$ Cannon T, Mobarek D, Wegge J, Tabbara IA: Hairy cell leukemia: current concepts. Cancer Invest 2008;26:860-865.

2 Ewald O: Die leukämische Reticuloendotheliose. Dtsch Arch Klin Med 1923;142:222-228.

3 Bouroncle BA, Wiseman BK, Doan CA: Leukemic reticuloendotheliosis. Blood 1958;13:609-630.

-4 Siegel R, Naishadham D, Jemal A: Cancer statistics, 2013. CA Cancer J Clin 2013;63:11-30.

5 Bouroncle BA: Thirty-five years in the progress of hairy cell leukemia. Leuk Lymphoma 1994;14(suppl 1):112.

6 Schrek R, Donnelly J: Hairy cells in blood lymphoreticular neoplastic disease and 'flagellated' cells of normal lymph nodes. Blood 1966;27:199.

7 Riccioni R, Galimberti S, Petrini M: Hairy cell leukemia. Curr Treat Options Oncol 2007;8:129-134.

8 Tiacci E, Trifonov V, Schiavoni G, Holmes A, Kern W, Martelli MP, et al: BRAF mutations in hairy-cell leukemia. N Engl J Med 2011;364:2305-2315.

-9 Kreitman RJ: Hairy cell leukemia - new genes, new targets. Curr Hematol Malig Rep 2013;8:184-195.

10 Mercieca J, Matutes E, Moskovic E, MacLennan K, Matthey F, Costello C, et al: Massive abdominal lymphadenopathy in hairy cell leukaemia: a report of 12 cases. Br J Haematol 1992;82:547-554.

11 Mehta AB, Catovsky D, O’Brien CJ, Lott M, Bowley N, Hemmingway A: Massive retroperitoneal lymphadenopathy as a terminal event in hairy cell leukaemia. Clin Lab Haematol 1983;5:259-263.

12 Kaw YT, Artymyshyn RL, Schichman SA, Salhany KE: Recurrent hairy cell leukemia presenting as a large mesenteric mass diagnosed by fine needle aspiration cytology. A case report. Acta Cytol 1994;38:267-270.

13 Zák P, Chrobák L, Podzimek K, Hejcmanová D, Voglová J, Dulícek P, Mirová S: An unusual course in hairy-cell leukemia with marked abdominal lymphadenopathy, leukemic infiltration of the cornea and skin changes. Vnitr Lek 1996;42:463-466. 


\section{Case Reports in Oncology}

\begin{tabular}{l|l}
\hline Case Rep Oncol 2013;6:493-496 & \multicolumn{2}{c}{$\begin{array}{l}\text { @ 2013 S. Karger AG, Basel } \\
\text { www.karger.com/cro }\end{array}$} \\
\hline DOI: $10.1159 / 000355434$ &
\end{tabular}

Shackelford et al.: Marked Retroperitoneal Lymphadenopathy in Hairy Cell Leukemia: A Case Report

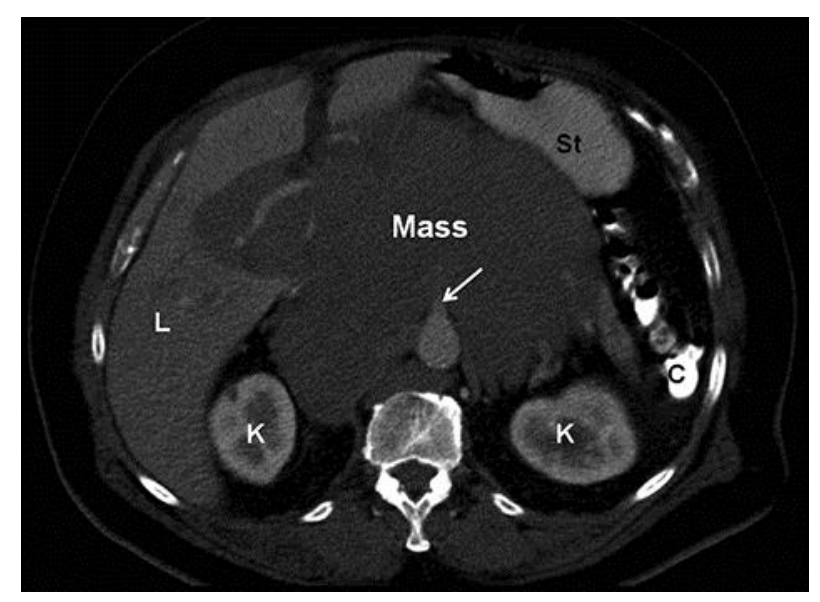

Fig. 1. Axial CT with intravenous and gastrointestinal contrast. A large homogeneous retroperitoneal mass encases the superior mesenteric artery (arrow), displaces the stomach (St) and insinuates into the hepatic hilum. $\mathrm{L}=$ Liver; $\mathrm{K}$ = kidney; $\mathrm{C}=$ colon.
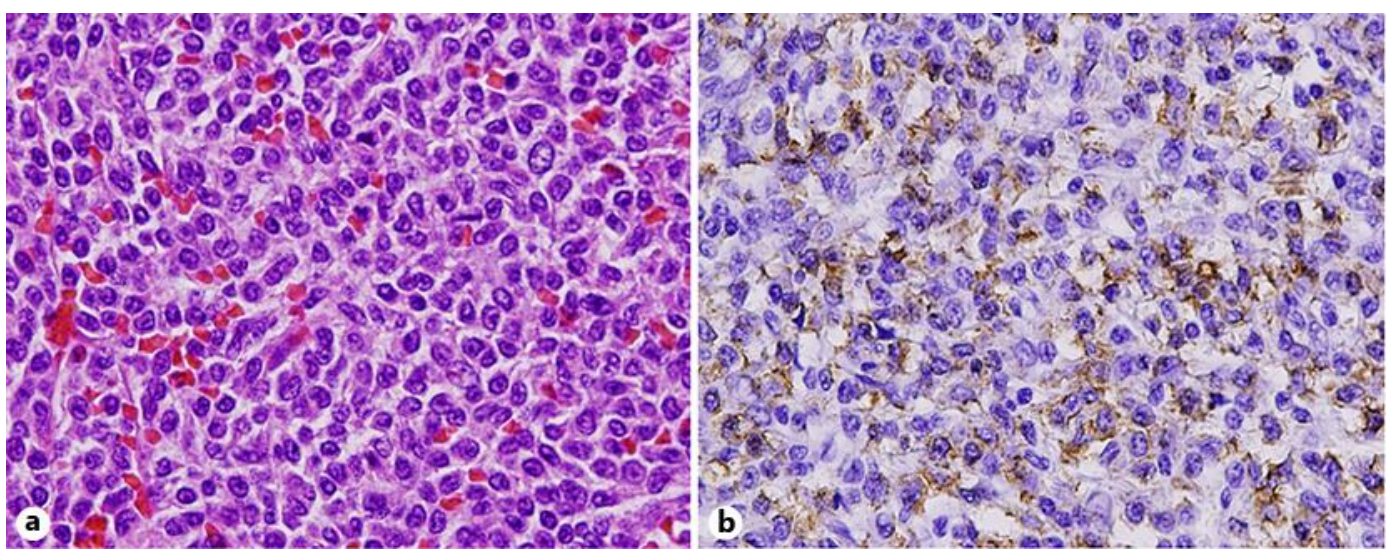

Fig. 2. Representative HE and IHC results for the retroperitoneal mass. a High-power of the retroperitoneal HCL showing characteristic cell morphology. b IHC showing TRAP staining positivity, typical of HCL [5-7]. 